\title{
Saúde pública: suporte á saúde dos turistas durante a copa
}

\section{4}

Public health: health support of tourists during the world cup 2014

Maria Cristina de Alencar Silva ${ }^{1}$

\section{Resumo}

O presente estudo tenciona fazer uma análise jurídica, econômica e social da capacidade de suporte do serviço público brasileiro de saúde em relação às necessidades advindas da realização do grande evento esportivo denominado Copa 2014. Buscou-se embasar a análise ora proposta, por intermédio de notas públicas, documentos e programas divulgados pelo governo e desta fazer algumas reflexões construtivas e apontar alguns pontos positivos e negativos da aplicação de recursos públicos em um evento de curta duração, mas que se constitui em longo tempo de organização financeira e de infraestrutura para atender adequadamente os atores que farão parte deste megaevento desportivo. A discussão é meramente reflexiva, pois somente após a realização do evento será possível analisar os benefícios e malefícios gerados por ele, quando comparado ao mesmo evento ocorrido em outros países.

Palavras-chave: Eventos Esportivos. Saúde. Eficiência do Estado.

\section{Abstract}

This study aimed to analyze legal, economic and social carrying capacity of the Brazilian public health service in relation to needs arising from the completion of major sporting event called the World Cup 2014. Was tried to base the analysis proposed here, through public notes, documents and programs released by this government and make some constructive thoughts and point out some positives and negatives of public resources in an event of short duration, but it is long-time financial organization and infrastructure to adequately meet the actors taking part in this megasporting event. The discussion is merely reflective, because only after the event will be possible to analyze the benefits and harm caused by it, compared to the same event in other countries.

Key words: Sporting Events. Health. Efficiency of State.

1 Advogada. Mestranda em Direito e Politicas Públicas na Uni-CEUB, Brasilia, DF. 


\section{Introdução}

A realização da Copa do Mundo de 2014 no Brasil tem sido motivo de grande polêmica na sociedade brasileira. Alguns são defensores do evento e acreditam que será uma grande oportunidade para a geração de investimentos em infraestrutura e desenvolvimento interno que ficarão como legado para a população. No entanto, outros desacreditam em tais projetos e dizem que o evento trará gastos públicos desnecessários e que o valor investido, principalmente nos estádios e em seu entorno, deveria ser investido em setores como saúde, educação e segurança.

Dentre os países que planejaram grandes eventos, os casos de sucesso foram a Espanha em 1992 e Austrália, em 2000, que sediaram os Jogos Olímpicos. O que ambos tiveram em comum para o sucesso foi o planejamento prévio para reduzir valores das obras, investimento direcionado para a infraestrutura urbana incluindo a revitalização de áreas urbanas degradadas, além da promoção turística da cidade e do país no exterior.

Segundo um estudo do DIEESE (2012), dentre os vários impactos na economia de países que sediaram a Copa do Mundo, há diferenças entre os resultados para países desenvolvidos e em desenvolvimento. Naqueles em desenvolvimento, a experiência da África do Sul, em particular, aponta alguns dos problemas a serem enfrentados: número de turistas aquém do esperado; subutilização dos estádios pós-copa e poucos investimentos em infraestrutura em um país com graves problemas sociais.

Para o Sindicato da Arquitetura e da Engenharia - SINAENCO (2009), os números comprovam que a Copa do Mundo tem grande apelo midiático em qualquer país onde seja realizada e que tal evento é uma vitrine capaz de mostrar a milhões de telespectadores, vários aspectos que vão além de estádios e disputas esportivas.

Oliveira e Gaffney (2010) comentaram que a disputa por megaeventos tem se tornado cada vez mais acirrada, onde, a partir de um diagnóstico de inexorabilidade da globalização, uma agenda determinada pela lógica do mercado tem dominado as teorias e as práticas do planejamento de cidades.

Para Barclay, (2009), baseado em análise de outros megaeventos desportivos, o endividamento público e a falta de planejamento para o pós-evento 38

Revista de DiReito Público, LondRINA, V. 7, N. 3, P. 37-52, SET./DEZ. 2012. 
pode provocar a subutilização das infraestruturas construídas, produzindo alto custo de manutenção.

Segundo Simon Kuper e Stefan Szymanski (2011), sediar torneios esportivos não deixa um país rico, sendo que o real motivo pelo qual os países anseiam sediar um megaevento é deixar sua população feliz. Esses autores realizaram uma análise de dados estatísticos e matemáticos para descrever a economia e até a sociologia do futebol e como ele reflete a sociedade em diferentes países. Comentaram ainda, que no Brasil o nível de corrupção é alto e que os resultados podem ser comprados.

A evidência pelo mundo afora sugere que um Estado capacitado com instituições governamentais boas e transparentes está associado ao alto crescimento da renda, saúde nacional e realizações sociais. Rendas mais altas, investimento e crescimento, assim como maior expectativa de vida encontram-se em países com instituições governamentais efetivas, honestas e meritocráticas, com regulamentações claras e também onde o papel do direito é aplicado de maneira justa e onde a sociedade civil e a mídia têm voz independente, acentuando a responsabilidade de seus governos.

Sendo público e notório que a corrupção se reflete no futebol, o que esperar das obras públicas a ser realizadas em nome deste evento tão esperado. No Brasil, os casos publicados sobre desvios de verba da saúde, a falta de leitos, a falta de equipamentos, de médicos e até mesmo de medicação, são incontáveis.

\section{Análise econômica de suporte à saúde para a Copa 2014}

As políticas públicas voltadas para a saúde, embora bem idealizadas, não são colocadas em prática, fato que gera a desorganização e a escassez ou ausência de investimentos adequados. Desta forma, permanecem as lacunas que precarizam o estado da saúde brasileira e dificultam o atendimento de melhor qualidade aos cidadãos que necessitam da infraestrutura pública.

O art. 198 da Constituição Federal (BRASIL, 1988) definiu em seu parágrafo 3ํ, a criação de Lei Complementar, que deve reavaliar no mínimo a cada cinco anos o estabelecimento de percentuais, normas de fiscalização, avaliação e controle das despesas com saúde nas três esferas de governo. 
Em 2012 a Lei Complementar no 141(BRASIL, 2012), de 13 de janeiro de 2012 entrou em vigor, estabelecendo no art. 6o que os Estados e o Distrito Federal aplicarão, anualmente, em ações e serviços públicos de saúde, no mínimo, 12\% (doze por cento) da arrecadação dos impostos a que se refere o art. 155 e dos recursos de que tratam o art. 157, a alínea "a" do inciso I e o inciso II do caput do art. 159, todos da Constituição Federal, deduzidas as parcelas que forem transferidas aos respectivos municípios.

Ao comparar a estimativa do Ministério da Saúde com a apresentada pela Organização Mundial de Saúde - World Health Statistics (WHO, 2012), percebe-se uma grande diferença entre o Brasil e os outros países que têm sistema de saúde universal. A diferença não está no volume total de recursos aplicados em saúde, mas na participação dos recursos públicos neste total.

De acordo com WHO (2012), no Brasil, o percentual do PIB (Produto Interno Bruto) investido na saúde até 2004 foi de 7\%, passou para 8\% no período de 2005 a 2008 e para 9\% a partir de 2009 até 2010. Neste mesmo período, segundo dados da mesma fonte a Espanha investiu 7\% do PIB de 2000 a 2002, 8\% de 2003 a 2007, 9\% em 2008 e 10\% em 2009 e 2010, conforme se verifica na figura 1.

Figura 01 - Investimento em saúde (PIB\%). Comparação entre Brasil e Espanha entre os anos de 2005 e 2010.

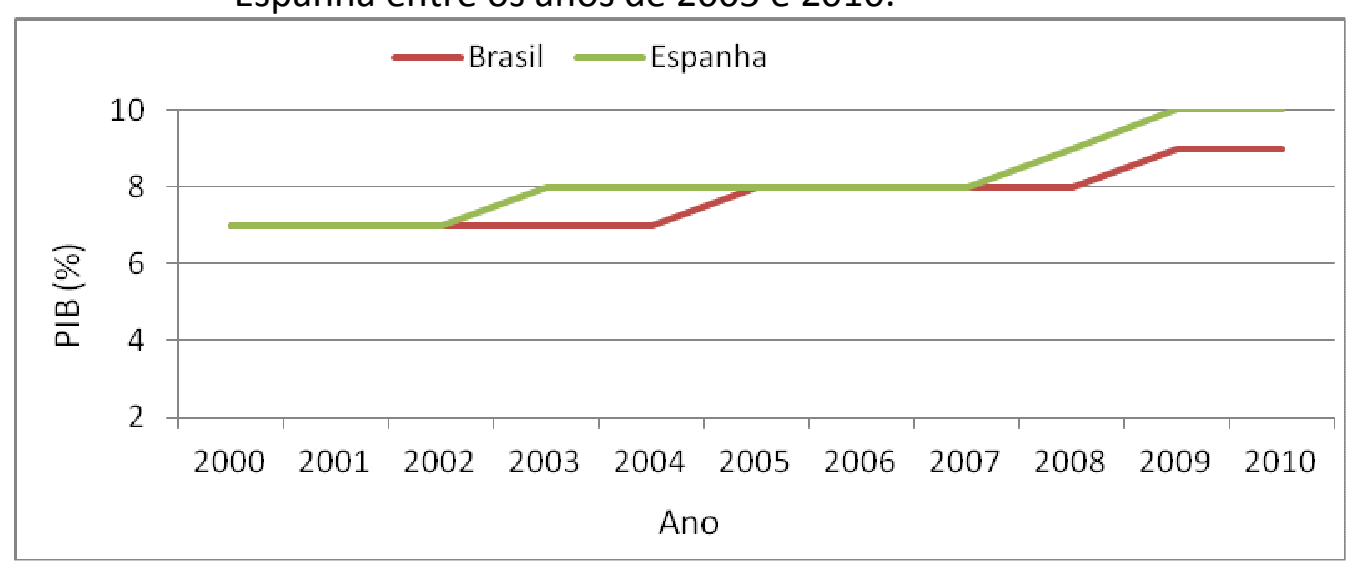

Fonte: World Health Statistics - WHO (2012)

Salienta-se que o valor per capita em paridade de poder de compra (PPP, sigla da expressão em inglês purchasing power parity) do gasto governamental do Brasil foram estimados em US\$ 333 (2005), US\$ 323 (2006), US\$ 348 (2007), US\$ 385 40 
(2008) e US\$ 401 (2009). O percentual relativo ao PIB destinado à saúde não tem acompanhado os gastos públicos per capita e quando faz, não é realizado com qualidade e eficiência.

De acordo com o Instituto de Pesquisa Econômica Aplicada - IPEA (2012), o Brasil investiu 3,7\% do PIB em 2010, crescimento de apenas 1,27\% nos últimos 10 anos, enquanto os países desenvolvidos investiram em torno de $7 \%$. Se for realizada uma comparação a partir de valores per capita, observa-se uma grande distância entre o Brasil e outros países. Os gastos da Espanha, como exemplo, foram de: US\$ 1.602 (2005), US\$ 1.757 (2006), US\$ 1.917 (2007), US\$ 2.049 (2008) e US\$ 2.258 (2009), registrando valores superiores de reajuste em relação ao Brasil.

De acordo com Departamento Intersindical de Estatística e Estudos Socioeconômicos - DIEESE (2012) a Copa do Mundo em países desenvolvidos, como exemplo os Estados Unidos, em 1994, não necessitou de grandes investimentos em infraestrutura, uma vez que o país já possuía a estrutura necessária para um evento de tal porte. O contrário acontece para países em desenvolvimento, sem infraestrutura consolidada.

Apesar dos investimentos, de acordo com pesquisa realizada pela Confederação Nacional das Indústrias - CNI (2012), 61\% da população brasileira consideram o serviço público de saúde do país péssimo ou ruim; $54 \%$ consideram o serviço público de saúde de sua cidade péssimo ou ruim e $85 \%$ dos entrevistados não perceberam avanços no sistema público de saúde do país nos últimos três anos.

Como se percebe, o Brasil ainda está longe de alcançar o desenvolvimento no âmbito da saúde, mesmo com os investimentos destinados ao evento da Copa 2014. Apesar de estar ocupando a sexta economia do mundo, o Brasil, ainda é o 94응 colocado em mortalidade infantil, de acordo com a ClA - The Word Factbook (2011).

No ranking de países com boas condições para o turismo, publicado pelo The Travel \& Tourism Competitiveness Report (2011), o Brasil está classificado em 70 lugar nas Américas e 52 no geral. Quanto aos maiores problemas percebidos em relação à saúde, está à proteção e à segurança, no ranking 75‥ Quanto à saúde e higiene está em 73ㅇ lugar. Salienta-se, que esses itens melhoraram bastante desde a última avaliação em 2009. 


\section{Estratégias do Ministério da Saúde para a Copa 2014}

De acordo com o Brasil (2012) o Ministério da Saúde montou uma Câmara Temática, onde são reunidos representantes do Ministério e das Secretarias de saúde das cidades que serão sede da Copa do Mundo de Futebol de 2014 para debater, elaborar planos e preparar campanhas preventivas sobre possíveis surtos e epidemias.

Nesses encontros da Câmara são discutidos como será realizado o monitoramento nas regiões turísticas e a organização da rede assistencial pública e privada para atender as demandas durante o evento. Segundo o coordenador da Câmara Temática e Secretário-Executivo adjunto do Ministério da Saúde, as ações previstas não têm como objetivo criar investimento específico para a Copa e sim avançar no processo organizativo do Sistema Único de Saúde - SUS.

A diretoria da Rede de Atenção às Urgências e Emergências pretende definir pactos para os serviços de saúde públicos, filantrópicos e privados mapeando os serviços de urgência, capacitando profissionais e identificando serviços de referência para atendimento aos turistas, serão oferecidos aos voluntários da Força Nacional do SUS cursos de gestão de crises e oficinas de sensibilização.

A Secretaria de Vigilância em Saúde realizará ações de vigilância sanitária preventivas de surtos e epidemias. Pretende preparar respostas imediatas às emergências durante a Copa 2014. Entre as ações está a vacinação dos taxistas, profissionais de hotelarias, empresas aéreas e aeroportos contra rubéola e sarampo até 30 dias antes do início dos eventos. Ainda, haverá a elaboração de material destinado aos profissionais de saúde e aos diretamente ligados ao evento para aprimorar a notificação de casos de doenças.

A Agência Nacional de Vigilância Sanitária (ANVISA) se comprometeu a visitar as 12 cidades-sede para fazer a preparação das ações de monitoramento de risco sanitário nos setores de alimentação, água e estabelecimentos de saúde.

O Ministério da Saúde (BRASIL, 2012) informou que sua grande aposta é a chamada Rede de Atenção às Urgências (RAU), que promete fazer a promoção e a prevenção de doenças. Para isso, haverá uma valorização das Unidades de Pronto Atendimento (UPA's) e dos serviços 24 horas, a cobertura de 100\% do SAMU 192. 
Paralelamente, será criada uma rede de inovação tecnológica nas linhas de cuidados prioritários, como AVC e infarto agudo do miocárdio. Segundo a informação no site (Portal 2014), o planejamento está sendo conduzido desde o início do ano 2011 com a criação de grupos de conduta da saúde, que visitam as cidades-sede e diagnosticam o que é necessário naquela região.

\section{Suporte à saúde pública do turista estrangeiro durante a Copa 2014}

O Dicionário Aurélio (FERREIRA, 1979) define como turista, pessoas com permanência em lugares distintos daqueles que vivem, por um período de tempo inferior a um ano consecutivo, com fins de lazer, negócios e outros.

Segundo o Portal 2014 (2011), o projeto da Lei Geral da Copa de 2014 (PL 2330/11) facilitará a entrada de estrangeiros no país durante a Copa, conforme a proposta, até 31 de dezembro de 2014 , onde serão concedidos vistos de entrada no país, para todos que possuírem ingressos ou confirmação de aquisição de ingressos válidos para qualquer evento e todos que demonstrem seu envolvimento oficial com o evento.

De acordo com as estimativas do Departamento de Estudos e Pesquisas do Ministério do Turismo, meio milhão de turistas estrangeiros devem chegar ao Brasil para acompanhar a Copa 2014. Mas, segundo um estudo denominado Documento Referencial do Turismo no Brasil 2011/2014, conduzido pela Fundação Getúlio Vargas (BESSI, 2010), este número alcançará 2,98 milhões de pessoas. O grande desafio é oferecer uma infraestrutura de saúde de boa qualidade para um contingente tão grande.

A condição jurídica do estrangeiro no Brasil é definida pela Lei $n=6.815$, de 19 de agosto de 1980 D - 086.715/1981, bem como outros decretos e resoluções pertinentes a luz da Constituição Federal de 1988, dita Constituição Cidadã. Vale salientar que o Estatuto do Estrangeiro se inspira no atendimento à segurança nacional, na organização institucional e nos interesses socioeconômicos, políticos, culturais e, principalmente, na defesa do trabalhador nacional.

A Constituição Federal de 1988 trata especificamente do direito à saúde como direito social, no artigo 196, proclamando que "... o direito á saúde é um direito 
de todos e um dever do Estado". O Brasil tem um Acordo Internacional de Previdência Social com nove países em que o atendimento médico é público, desde que o imigrante esteja com a situação regularizada.

Neste contexto, os direitos e deveres básicos de cada cidadão brasileiro são estendidos ao estrangeiro que em solo brasileiro se encontre. Segundo a Lei 006.964, de 1981. O estrangeiro residente no Brasil goza de todos os direitos reconhecidos aos brasileiros, nos termos da Constituição, conforme o art. 5o "Todos são iguais perante a lei, sem distinção de qualquer natureza, garantindo-se aos brasileiros e aos estrangeiros residentes no país a inviolabilidade do direito à vida, à liberdade, à igualdade, à segurança e à propriedade".

De acordo com Lima (2012), levando em conta o espírito humanitário que inspira todo o ordenamento constitucional, conclui-se que qualquer pessoa pode ser titular de direitos fundamentais. Para o autor, o importante é que a pessoa esteja de algum modo, sob a jurisdição brasileira, pois segundo ele, em observação a Constituição, em nenhum momento, diz expressamente que os estrangeiros não residentes no país não podem exercer os direitos fundamentais. Apenas silencia a respeito.

No Brasil, segundo o Ministério da Saúde (2012), não há regras para os casos de emergência, em que todos são atendidos, independentemente de sua nacionalidade. Entretanto, nos casos em que não há urgência, apenas os imigrantes residentes e trabalhadores de forma regularizada têm direito ao atendimento gratuito no sistema público de saúde.

De acordo com Andrade (2012) a universalidade do atendimento presente no ordenamento jurídico brasileiro está relacionada à gratuidade no acesso aos serviços, independentemente de nacionalidade, classe social ou contribuição para o Fundo Nacional de Saúde, respeitando-se as Declarações, Pactos e Tratados Internacionais de direitos humanos assinados pelo Brasil.

\section{Situação de infraestrutura da saúde para as capitais que sediarão a COPA} 2014 
De acordo Ernest \& Young (2010) em parceria com a Fundação Getúlio Vargas (FGV), as cidades que sediarão os jogos da Copa serão alvo de iniciativas de infraestrutura que no total somarão investimentos da ordem de $\mathrm{R} \$ 14,54$ bilhões, sendo parte desses investimentos custeada pelo governo e o restante bancado pelo setor privado e pelas instituições associadas à Copa do Mundo, o que de acordo com Bastos e Cobos (2010) é a busca pelo BNDES (Banco Nacional do Desenvolvimento Econômico e Social) de recursos em empréstimos feitos junto às condições e operações de mercado.

Com base no estudo realizado por Domingues et al. (2012) encomendado pelo Ministério do Esporte, foi estimado que o impacto econômico dos Jogos Olímpicos e Paraolímpicos sobre o PIB (Produto Interno Bruto) do Brasil será de R\$ 22 bilhões até 2016, enquanto que, no período de 2017 a 2027, atingirá R\$27 bilhões.

Os gastos estimados para a Copa 2014, orçada em $\mathrm{R} \$ 25$ bilhões iniciais subiu para $\mathrm{R} \$ 27,4$ bilhões, segundo estudo divulgado pelo Tribunal de Contas da União (TCU, 2012). As cidades-sede que registraram o maior salto de investimentos foram São Paulo (R\$ 4,9 bilhões em março para R\$ 6,2 bilhões em junho), Natal (de $\mathrm{R} \$ 1$ bilhão para R\$1,7 bilhão) e Curitiba (R\$ 318 milhões para R\$ 863 milhões).

A maior fatia de recursos foi para a infraestrutura urbana que continua liderando a destinação de recursos com R\$ 12 bilhões, investidos em junho de 2012. Pouco foi previsto ou destinado para a saúde em termos de melhores hospitais, aumento no número de ambulâncias, leitos em unidades de emergência e atendimento em pronto socorro, permanecendo fora do relatório.

Segundo uma pesquisa realizada em 2010 pela Meta Pesquisa de Opinião com 5.000 pessoas em todo o Brasil, sendo 1.078 realizadas com pessoas que habitavam as cidades que sediarão a Copa 2014, apenas 7,2\% das pessoas colocaram como prioridade a saúde e a rede de hospitais em sua cidade. Isto significa que as pessoas não se dão conta da necessidade de infraestrutura de saúde, até o momento que necessitam dela.

Mattos e Barcellos (2010) fizeram um levantamento bibliográfico com 41 artigos relacionados à saúde do turista estrangeiro em vários países. Verificam nos trabalhos analisados, que dentre as principais reclamações dos turistas em relação à 
saúde está à picada de insetos em ambientes tropicais, seguida de diarreia, oriunda de água não tratada e alimentos contaminados. Os autores comentaram que a falta de dados específicos a respeito da saúde de turistas é a principal causa da dificuldade de relacionar doenças específicas com as atividades de turismo.

É sabido que a situação das capitais que sediarão a Copa 2014 é extremamente diferente entre si, de modo que poucas possuem boa infraestrutura, principalmente de saúde. Exemplo disso foi o estudo conduzido pelo Instituto Trata Brasil em conjunto com a Fundação Getúlio Vargas (FGV, 2009) que orçou entre 2003 e 2007, a necessidade de saneamento em 79 cidades brasileiras, dentre elas, as capitais que sediarão o evento da Copa 2014. Foi constatado que no período, o avanço do atendimento de esgoto foi de $14 \%$, enquanto o de tratamento de água cresceu cerca de $5 \%$, significando que as 12 cidades-sede têm um caminho de quase R\$ 7 bilhões a percorrer para que seus serviços de saneamento básico sejam universalizados.

Além do problema do saneamento básico em algumas cidades-sedes, que podem causar contaminações gastrointestinais, há as questões especificas de cada região, tal como as doenças tropicais como a malária, leishmaniose e a dengue, sendo esta última, comum em vários Estados brasileiros. Nas cidades de praias, há a questão da limpeza, da sua balneabilidade e têm-se ainda, os afogamentos.

Outra questão muito importante é a alimentação, típica de cada cidade, que normalmente atraem a atenção dos turistas, devendo-se dar atenção especial às boas práticas alimentares para se evitar as intoxicações alimentares pelos turistas, principalmente à comida de rua, tão apreciada pelos turistas.

As diferenças climáticas também são relevantes, pois enquanto no sul do Brasil, no mês de julho a temperatura pode chegar a abaixo de zero, no norte e centro-oeste pode chegar a quarenta graus. De acordo com Confalonieri (2003), muitas doenças estão relacionadas à variabilidade climática e existem várias doenças infecciosas endêmicas que são sensíveis às variações do clima, principalmente aquelas de transmissão vetorial e, também, por veiculação hídrica.

Considerando a diversidade climática, gastronômica, e, principalmente de infraestrutura no atendimento à saúde. As capitais que sediarão a Copa 2014 terão 
que estar muito bem preparadas para receber o grande fluxo de turistas estrangeiros que estarão ansiosos para experimentar toda essa diversidade e também devem estar muito bem preparadas para arcar com os custos advindos de tal evento.

Indiscutivelmente, São Paulo é o centro do Brasil, em todos os sentidos. É uma capital referência na saúde, na educação e na infraestrutura urbana, embora ainda fique a desejar no que tange ao transporte urbano, ante ao número de usuários que aumenta a cada ano.

O Rio de Janeiro está no centro da produção global do espetáculo esportivo, sediará a Copa 2014 e os Jogos Olímpicos 2016 e já sediou os Jogos Pan-americanos em 2007, desta forma já possui experiência em grandes eventos. No entanto, a violência ainda é um dos seus maiores problemas.

Curitiba é a cidade que mais se destaca em infraestrutura urbana e na saúde. É referencial nacional para a rede de transporte e para tratamentos de saúde em hospitais públicos e privados.

Belo Horizonte conta com hospitais qualificados para o atendimento à necessidade de tratamento especializado para atletas, mas, o atendimento não será exclusivo aos atletas, necessitando, portanto, de uma boa infraestrutura de atendimento rápido à saúde.

As demais capitais ficam a desejar no quesito infraestrutura da saúde, pois não são referenciais, muito pelo contrário, nelas se encontram os problemas regionais ligados à variabilidade climática (que engloba temperatura, baixa em Porto Alegre e alta no centro-oeste e norte, que não possibilitam conforto climático). Além das inevitáveis picadas de insetos, haverá a qualidade do saneamento básico, as comidas tradicionais, mas exóticas aos turistas e o perigoso atendimento sexual aos turistas estrangeiros que poderá resultar em doenças transmissíveis, contribuindo com aumento de pacientes para este tipo de atendimento após o término do evento, aumentando os gastos públicos com a saúde nas cidades sede.

Como questionam Swinnen e Vandemoortele (2008) se o financiamento dos mega-eventos com recursos públicos realmente promove um retorno mais eficiente quando comparado com os retornos de outras formas de investimentos, como por exemplo, no sistema de saúde e de educação, somente a experiência dirá. 


\section{Considerações Finais}

Considerando a atual situação de saúde no Brasil e a condição a ser ofertada aos nossos ilustres visitantes estrangeiros em tempo de copa no país, tal como a capacidade de suporte de atendimento à saúde nas capitais onde ocorrerão os jogos, bem como naquelas que serão visitadas pela oportunidade da vinda ao Brasil por esses turistas observa-se que a infraestrutura relativa aos serviços básicos de saúde deve sofrer várias reformas. Sob o ponto de vista de igualdade aos direitos básicos de assistência a saúde entre brasileiros e estrangeiros, não se pode apostar em um atendimento de saúde de qualidade durante o período da Copa 2014 em todas as cidades-sede.

Repetindo as palavras ditas por Ernest \& Young (2010) "O Brasil terá tido sucesso com a realização da Copa 2014 se conseguir alcançar os objetivos de forma economicamente eficiente, sem dispêndios excessivos, má alocação de recursos ou custos de oportunidade", assim, vislumbrando-se os investimentos financeiros que estão sendo e ainda serão direcionados em prol do megaevento desportivo que será a Copa 2014, espera-se que o Brasil realmente possa ter como legado os investimentos em saúde e que toda a infraestrutura montada tenha funcionalidade e seja de fato de uso da comunidade que dela necessita.

\section{Referências}

ANDRADE, Z.T.M. 2012. Da efetivação do direito à saúde no Brasil. Revista Âmbito Jurídico. Disponível em:

<http://www.ambitojuridico.com.br/site/?n_link=revista_artigos_leitura\&artigo_id= 9037\&revista_caderno=9>. Acesso em: 08 jun. 2012.

BARCLAY, J. 2009. Predicting the costs and benefits of mega-sporting events: misjudgement of olympic proportions? Economic Affairs, v. 29, n. 2, p. 62-66, jun.

BASTOS, M; COBOS, P. Verba pública financiará $94 \%$ dos estádios da Copa. Documento do Ministério do Esporte mostra que país vai gastar $\mathrm{R} \$$ 5,3 bilhões. Folha de São Paulo. P. D1. Fevereiro de 2010.

BRASIL. 1988 - CONSTITUIÇÃO FEDERAL. Art. 198. Criação de lei complementar. Disponível em: 
<http://www.planalto.gov.br/ccivil_03/constituicao/constitui\%C3\%A7ao.htm>. Acesso em: 20 jun. 2012.

BRASIL, 2012. LEI COMPLEMENTAR № 141, DE 13 DE JANEIRO DE 2012. Estabelece os critérios de rateio dos recursos de transferências para a saúde e as normas de fiscalização, avaliação e controle das despesas com saúde nas 3 (três) esferas de governo... Disponível em:

<http://www.planalto.gov.br/ccivil_03/leis/lcp/Lcp141.htm>. Acesso em: 08 ago. 2012.

BRASIL. Ministério da Saúde. 2012. Preparativos: Saúde debate ações para Copa do Mundo de 2014. Disponível em:

$<$ http://portalsaude.saude.gov.br/portalsaude/noticia/4796/162/saude-debateacoes-para-copa-do-mundo-de-2014.html>. Acesso em: 25 maio 2012.

BRASIL. Ministério do Turismo. 2010. Turismo de Saúde: orientações básicas. Ministério do Turismo, Secretaria Nacional de Políticas de Turismo, Departamento de Estruturação, Articulação e Ordenamento Turístico, Coordenação-Geral de Segmentação. - Brasília: Ministério do Turismo, 59 p.

$\mathrm{CIA}$ - Central Intelligence Agency. The Word Factbook - People and society Brazil. Disponível em: <https://www.cia.gov/library/publications/the-worldfactbook/geos/br.html>. Acesso em: 28 jun. 2012.

CONFALONIERI, U.E.C. 2003. Variabilidade climática, vulnerabilidade social e saúde no Brasil. Terra Livre, São Paulo, Ano 19, vol. I, no 20. jan/jul. p. 193-204. Disponível em: <http://www.bvsde.paho.org/bvsacd/cd68/UConfalonieri2.pdf>.

Acesso em: 16 jun. 2012.

DEPARTAMENTO INTERSINDICAL DE ESTATÍSTICA E ESTUDOS SOCIOECONÔMICOS DIEESE. 2012. Copa do Mundo 2014: algumas considerações sobre a realização do evento no Brasil. Nota Técnica № 110. Disponível em: $<$ http://www.dieese.org.br/notatecnica/notaTec110Copa.pdf>. Acesso em: 27 maio 2012.

DOMINGUES, E. P. Copa 2014: Impactos econômicos no Brasil, em Minas Gerais e Belo Horizonte. 2012. Disponível em:

<http://www.cedeplar.ufmg.br/seminarios/seminario_diamantina/2010/D10A119.pd f>. Acesso em: 02 maio 2012.

ERNEST \& YOUNG. 2010. Brasil sustentável: Impactos Socioeconômicos da Copa do Mundo 2014. São Paulo. 56p. Disponível em: 
<http://www.sebrae.com.br/setor/couro-e-calcados/sobrecouroecalcados/mercadointerno/Brasil_Sustentavel_Copa_do_Mundo_2014.pdf>. Acesso em: 01 jun. 2012.

FERREIRA, A.B.H. Pequeno dicionário brasileiro da língua portuguesa. Ed. Civilização Brasileira S.A. v. 3. 1979.

FUNDAÇÃO GETÚLIO VARGAS - FGV. 2009. Copa requer $R \$ 7$ bi para o saneamento básico. Disponível em: <http://www.cps.fgv.br/ibrecps/clippings/lc1114.pdf>. Acesso em: 15 jun. 2012.

IPEA - Instituto Pesquisa Econômica. IPEA avaliou situação do governo na área social. Disponível em: <http://www.ipea.gov.br/portal/>. Acesso em: 20 jun. 2012.

KUPER, S.; SZYMANSKI, S. Soccernomics. Harper Collins Publishers, 2012. 400p.

Lei 006.815-1980. Situação Jurídica do Estrangeiro no Brasil - Conselho Nacional de Imigração - Disponível em: <http://www.dji.com.br/leis_ordinarias/1980-006815sje/sje_095a110.htm>. Acesso em: 08 jun. 2012.

LIMA, G. M. Titularidade de direitos fundamentais por estrangeiros não residentes no país. Disponível em: <http://direitosfundamentais.net/2008/04/29/titularidade-dedireitos-fundamentais-por-estrangeiros-nao-residentes-no-pais/>. Acesso em: 20 jun. 2012.

MATOS, V.; BARCELLOS, C. Relações entre turismo e saúde: abordagens metodológicas e propostas de ação. Rev Panam Salud Publica. Disponível: 28(2):12834, 2010. Disponível em: <http://www.scielosp.org/pdf/rpsp/v28n2/a09v28n2.pdf>. Acesso em: 15 jun. 2012.

META PESQUISAS DE OPINIÃO. 2010. Relatório de Pesquisa quantitativa: Copa do mundo 2014. 87p. Disponível em: <http://www.secom.gov.br/sobre-asecom/pesquisas/2010-05-copa-2014/2010-05-copa-do-mundo-2014-cidadessede.pdf>. Acesso em: 15 jun. 2012.

OLIVEIRA, N.G.; GAFFNEY, C. T. 2010. Rio de Janeiro e Barcelona: os limites do paradigma olímpico. Revista Bibliográfica de Geografía y Ciencias Sociales. Universidad de Barcelona. Vol. XV, no 895 (17), 5/ nov. de 2010. Disponível em: <http://www.ub.edu/geocrit/b3w-895/b3w-895-17.htm>. Acesso em: 15 jun. 2012.

PEREIRA, D.L.; LUPES, R. 2011. Olimpíadas e Copa do Mundo de Futebol no Brasil: implicações para a sociedade brasileira. Revista Digital. Buenos Aires - Ano 16 - № 157 - Jun. de 2011. Disponível em : 
<http://www.efdeportes.com/efd157/olimpiadas-e-copa-do-mundo-de-futebol-nobrasil.htm>. Acesso em: 15 jun. 2012.

Pesquisa CNI - IBOPE: Retratos da sociedade brasileira: saúde pública - (janeiro 2012) - Brasília: CNI, 2012.67.

PORTAL 2014. 2011. Audiência discute recepção de estrangeiros durante a Copa e Olimpíada. Disponível em:

<http://www.portal2014.org.br/noticias/8606/AUDIENCIA+DISCUTE+RECEPCAO+DE+ ESTRANGEIROS+DURANTE+A+COPA+E+OLIMPIADA.html>. Acesso em: 08 jun. 2012.

SINAENCO - Sindicato da Arquitetura e Engenharia. 2009. Vitrine ou vidraça: Desafios do Brasil para a Copa de 2014. 129p. Disponível em:

<http://www.sebrae.com.br/customizado/sebrae2014/sebrae-2014/estudos-e pesquisas/Relatorio\%20Sinaenco\%20\%20Desafios\%20do\%20Brasil\%20para\%20a\%20 Copa\%20de\%202014.pdf>. Acesso em: 08 jun. 2012.

SWINNEN, J.; VANDEMOORTELE, T. 2008. Sports and development: An economic perspective on the impact of the 2010 World Cup in South Africa. ICSSPE Bulletin, v.53, p. 1-6. Disponível em:

$<$ https://lirias.kuleuven.be/bitstream/123456789/182730/2/Swinnen+and>. Acesso em: 22 jun. 2012.

THE TRAVEL \& TOURISM COMPETITIVENESS REPORT. 2011. World Economic Forum. Disponível em:

<http://www3.weforum.org/docs/WEF_TravelTourismCompetitiveness_Report_2011 .pdf>. Acesso em: 08 jun. 2012.

THOMAS, V. et al. A qualidade do Crescimento. São Paulo: Edit.. UNESP, 2002.

Disponível em: <http://www.cefetsp.br/edu/eso/marcio/resumo_qualidade.pdf>. Acesso em: 28 maio 2012.

TRIBUBAL DE CONTAS DA UNIÃO - TCU. Relatório 2012. P.39. Disponível em: <http://portal2.tcu.gov.br/portal/page/portal/TCU/publicacoes_institucionais/relator ios/relatorios_atividades/2012_Relat\%C3\%B3rio_1\%C2\%BA_Trimestre_COM\%20ALT ERA\%C3\%87\%C3\%95ES.pdf>. Acesso em: 20 jul. 2012.

WHO - World HEALTH ORGANIZATION, 2012. Global Health Expenditure Database. Disponível em: <http://apps.who.int/nha/database/DataExplorer.aspx?d=1\&ws=1024897858>. Acesso em: 28 jun. 2012. 
Artigo recebido em 19/09/2012 e aprovado para publicação em 27/11/2012. 